\title{
AS POLÍTICAS EDUCACIONAIS E O DESAFIO DA PESQUISA NA FORMAÇÃO E NA PRÁTICA DO PROFESSOR DA EDUCAÇÃO BÁSICA*
}

\author{
Célia Maria Fernandes Nunes** \\ Maria Amália de Almeida Cunha***
}

\section{RESUMO}

Diante das exigências das políticas educacionais atuais, procuramos, neste artigo, problematizar acerca da necessidade de se repensar a formação e a prática docente, reativando a idéia de formar o professor/pesquisador. Como material empírico, analisamos pequenos excertos respondidos por uma amostra de alunos dos cursos de licenciatura da Universidade Federal de Ouro Preto que também são professores da rede pública de ensino. Embora se reconheça a importância dos documentos oficiais em privilegiar, nos cursos de formação, a construção do chamado professor/pesquisador, constatamos que uma política apenas de cunho vertical não é suficiente para a sua execução, pois requer a conjugação de esforços de todos aqueles inseridos no processo educativo.

Palavras-chave: professor/pesquisador; formação do professor; políticas educacionais; licenciaturas.

\section{CONSIDERAÇÕES INICIAIS ACERCA DE UMA PROBLEMÁtICA}

As transformações que vêm ocorrendo na sociedade têm refletido substantivamente nos sistemas de ensino, por meio da implementação de reformas educacionais. Tais mudanças vêm apresentando novas demandas para a educação e é neste contexto que as políticas educacionais

* Artigo recebido em 1/2/2007 e aprovado em 3/5/2007.

** Departamento de Educação. Universidade Federal de Ouro Preto. E-mail: cmfnunes@gmail.com

*** Departamento de Ciências Aplicadas à Educação. Universidade Federal Minas Gerais. Email: amalia.c@uol.com.br 
sinalizam para a importância do professor como uma categoria profissional relevante e imprescindível para a recuperação da qualidade da escola.

É, pois, neste cenário educacional que percebemos a necessidade de se repensar a formação e a prática do professor como elementos diretamente relacionados com o processo pedagógico, reativando a idéia de ensino como pesquisa. O professor então passa a ser reconhecido como um sujeito pesquisador de sua própria prática.

Esta nova perspectiva de pensar e refletir acerca da formação e atuação do professor considera a complexidade da prática docente e, assim, direciona-se para o desenvolvimento profissional do professor como um sujeito que reflete e indaga sobre o seu fazer, distanciando-se de uma visão tecnicista em que a ele é reservada a função de mero transmissor de conhecimentos e aplicador de técnicas para a solução de problemas. Sacristan (1995) chama a atenção para a importância de se adotar essa perspectiva, pois considera que a prática docente

não é uma ação que deriva de um conhecimento prévio, como acontece em certas engenharias modernas, mas, sim, uma atividade que gera cultura intelectual em paralelo com sua existência, como aconteceu com outras profissões sociais e ofícios. Isto é importante porque muitos dos especialistas em educação se esquecem deste fato quando chega a hora de refletir sobre a relação entre prática e conhecimento. Os problemas da prática não são ocos ou vazios de fundamentação científica, mas sim contradições que a própria prática origina. (SACRISTAN, 1995, p.70)

$\mathrm{Na}$ tentativa de compreender a complexidade da prática pedagógica, diversos estudos têm sido desenvolvidos junto a docentes, os quais buscam, através de um processo de reflexão-ação-reflexão, caracterizá-los como professor pesquisador. Tal denominação suscita algumas indagações, entre outras: o que é ser professor-pesquisador? A reflexão sobre a prática pode ser considerada pesquisa? O que é pesquisa? Pesquisar advém de um monopólio exclusivo da teoria?

No intuito de buscar respostas para estas perguntas e, conseqüentemente, possíveis contribuições para a reflexão sobre a formação docente, pretendemos neste artigo analisar o conceito de professor pesquisador na realidade educacional brasileira com base na literatura $\mathrm{e}$ nos documentos oficiais relacionados à área da formação de professores, 
levando em conta a nossa própria atuação profissional, como professoras dos cursos de licenciatura da UFOP-MG, atuando na formação de professores de educação básica.

\section{O PROFESSOR E A PESQUISA NO DISCURSO OFICIAL}

As políticas educacionais implementadas nos últimos anos têm trazido em seus documentos a respectiva problemática: que no processo de sua formação e de sua atuação educativa, o professor desenvolva competências e habilidades investigativas e seja considerado aquele que pesquisa sobre a sua prática.

Analisando a documentação referente às Diretrizes Curriculares Nacionais para a Formação de Professores da Educação Básica, em nível superior, curso de Licenciatura, de graduação plena (PARECER CNE/9/ 2001 e Resolução CNE/CP/1/2002), identificamos que um dos argumentos relativos à dificuldade de se estabelecer uma educação básica de qualidade encontra-se na fragilidade concernente ao preparo inadequado dos professores em sua formação de modo geral, não atendendo muitas das características consideradas imprescindíveis para a prática docente, sendo alguma delas: o desenvolvimento de práticas investigativas.

Percebe-se nos documentos o destaque que é conferido à pesquisa enquanto elemento essencial na formação profissional do professor (grifo do documento). Tal destaque considera a complexidade da prática docente, uma vez que o professor parece encontrar-se diante de constantes desafios e mediante situações que não se repetem nem podem ser cristalizadas no tempo. Surge então a necessidade de que ele elabore diferentes ações imediatas, intervindo no processo de ensino e aprendizagem, fato que o obriga, muitas vezes, a agir de forma improvisada diante das situações não planejadas.

Por essas razões, a pesquisa (ou investigação) que se desenvolve no âmbito do trabalho de professor refere-se, antes de mais nada, a uma atitude cotidiana de busca de compreensão dos processos de aprendizagem e desenvolvimento de seus alunos e à autonomia na interpretação da realidade e dos conhecimentos que constituem seus objetos de ensino. (PARECER CNE 9/2001, p. 28) 
Desta forma, o próprio processo de ensino e de aprendizagem dos conteúdos escolares da educação básica é considerado elemento principal do ensino da pesquisa nos cursos de formação docente.

Neste sentido é que temos percebido a ênfase que as políticas educacionais tem fornecido sobre a formação dos professores, sobretudo por constatar que, para singrar rumo a uma educação de qualidade, o professor deve desenvolver uma postura investigativa de forma autônoma. Para tanto, faz-se necessário que os professores sejam preparados de modo a conhecer e saber utilizar os procedimentos para o desenvolvimento da pesquisa, tais como o levantamento de hipóteses, a delimitação de problemas, o registro de dados, a sistematização de informações, a análise e comparação de dados, a verificação etc.

Assim, de posse desses conhecimentos, é que o professor será capaz de

produzir e socializar conhecimento pedagógico de modo sistemático. Ele produz conhecimento pedagógico quando investiga, reflete, seleciona, planeja, organiza, integra, avalia, articula experiências, recria e cria formas de intervenção didática junto aos seus alunos para que estes avancem em suas aprendizagens. (PARECER CNE 9/ 2001, p.28)

O texto apresentado na Resolução CNE/CP1 de 2002 destaca ainda que ao organizar o currículo dos cursos de formação de professores da Educação Básica, deve-se considerar, o aprimoramento para a prática investigativa. Neste sentido, a pesquisa deverá ser a "matéria-prima" no processo de ensino e de aprendizagem, já que a atividade de ensinar "requer, tanto dispor de conhecimentos e mobilizá-los para a ação, como compreender o processo de construção do conhecimento" (RESOLUÇÃo CNE/CP 1 de 2002, p. 2).

\section{A CONSTRUÇÃO DO PROFESSOR PESQUISADOR}

Os estudos que relevam o papel da pesquisa na formação docente percebem a prática educativa como uma atividade complexa que exige do professor uma postura reflexiva e que envolve constantemente a investigação como um instrumento necessário e eficaz para analisar e criar situações alternativas de ensino. 
Dessa forma, o docente, analisando a prática, sistematiza o novo conhecimento, desenvolvendo uma autonomia intelectual que o conduz permanentemente a pensar e a produzir mudanças. Tais tentativas de inovação promovem um avanço na prática do professor, pois, a cada nova situação, ele integra experiências anteriores em uma análise de compreensão atual, colocando-se em constante superação. O docente que faz uso dessa estratégia para conduzir a prática educativa tem sido caracterizado como professor pesquisador.

No entanto, o que podemos observar é que, tanto na prática como na literatura, este termo tem gerado mal-entendidos, já que de certa forma a reflexão se identifica com a pesquisa. Teriam eles o mesmo significado? Estariam caracterizando o mesmo processo? Embora reconhecendo a dificuldade de tornar mais precisos os referidos conceitos, arriscaríamos em dizer (em uma primeira aproximação) que o professor reflexivo pode ser considerado aquele que, levando-se em conta o valor da sua experiência docente, pode refletir acerca de sua atividade tendo como base $o$ conhecimento acumulado ao longo de sua prática e da reflexão teórica sobre sua prática. Já o professor pesquisador iria mais além, quando, ao considerar tal reflexão, produz um saber original ancorado em normas técnicas e científicas, as quais resultarão em um conhecimento sistematizado.

A tendência em valorizar o professor como um sujeito que reflete e pesquisa sobre sua ação tem estimulado o desenvolvimento de pesquisas acadêmicas, oriundas de uma prática de capacitação coletiva contínua entre professores. Assim, juntamente com um mediador (pesquisador), os professores procuram, a partir de dúvidas e questões apresentadas por eles mesmos, analisar as experiências vivenciadas, desenvolvendo uma forma de atualização mais concreta e coerente com o contexto em que atuam.

Estas pesquisas surgem inseridas em um movimento de crítica ao distanciamento da academia e à realidade da escola, reconhecendo e valorizando os saberes gerados na prática dos professores. Trata-se de estudos desenvolvidos junto a professores e que se enquadram nas investigações caracterizadas como pesquisa-ação, pesquisa colaborativa, pesquisa participante etc. Segundo Tardif, Lessard e Lahaye (1991), a pesquisa-ação é tida como a melhor alternativa para uma articulação entre teoria e prática, pois 
apesar de seu baixo nível de desenvolvimento, a pesquisa-ação poderia eventualmente oferecer um novo modelo de interação entre pesquisadores e docentes, teóricos e práticos. Esse modelo permitiria aos primeiros penetrar no meio escolar e aos segundos, fazer valer seu conhecimento e sua experiência. (apud FiorentinI et. al., 1998, p. 327)

O que percebemos é que pesquisas desta natureza possuem uma maior relevância social, pois envolvem os diferentes participantes que, juntamente com o pesquisador, buscam mudanças na prática educativa em uma dinâmica de reflexão contínua acerca de suas próprias ações. Pereira (1998), analisando a contribuição do pensamento de Elliott (1993), mostra-nos a ênfase por ele conferida, ao trazer "a pesquisaação como meio de produzir conhecimento sobre os problemas vividos pelo profissional, com vista a atingir uma melhora da situação, de si mesmo e da coletividade" (p. 154). Percebemos assim que o objetivo principal neste tipo de pesquisa refere-se mais à prática do que ao praticante, restando o desenvolvimento do professor, como pesquisador, como objeto secundário.

Perrenoud (1993), analisando a questão sobre o que seria o professor-investigador e, considerando as diferentes realidades, afirma:

o que é certo é que com a crescente implantação das ciências da educação nos sistemas escolares, torna-se ao mesmo tempo necessário, benéfico e possível associar os professores aos trabalhos de investigação. Já não se trata de abrir a sala de aula a um observador, de administrar testes e provas, de responder a questionários. Neste caso o professor desempenha um papel de sujeito de investigação ou de mediador, mas não de investigador, não é um professorinvestigador. (PERRENOUd, 1993, p. 128)

Lüdke (1998), apreciando a mesma questão e estribada em Zeichner (1998), infere o seguinte:

Hoje muitos professores sentem que a pesquisa educacional conduzida pelos acadêmicos é irrelevante para suas vidas nas escolas. A maior parte dos professores não procura a pesquisa educacional para instruir e melhorar suas práticas [...] Por outro lado, muitos acadêmicos nas universidades rejeitam a pesquisa dos professores das escolas por considerá-la trivial, a-teórica e irrelevante para seus trabalhos. A 
maioria dos acadêmicos envolvidos com o movimento de professorespesquisadores no mundo reduz o processo de investigação realizado pelos próprios professores a uma forma de desenvolvimento profissional e não o considera como uma forma de produção de conhecimento. (LUDKE, 1998, p. 207)

Tal distanciamento existente entre professores e pesquisadores tem sustentado a discussão a respeito de se considerar ou não os professores da escola básica como sujeitos produtores de conhecimentos, o que tem gerado questionamentos da seguinte natureza: que tipo de pesquisa deve o professor fazer para ser considerado pesquisador? Poderemos então considerar as diferentes atividades que o professor desenvolve, em sua prática cotidiana, como pesquisa? O que é pesquisa para o professor?

Podemos perceber a existência de uma vasta literatura que trata da importância da pesquisa no desenvolvimento do trabalho docente, assim como a defesa da figura do professor-pesquisador. No entanto, segundo Lüdke (2004),

é muito difícil encontrar trabalhos acadêmicos dedicados a enfrentar de perto a questão da propriedade do conceito de pesquisa corrente na academia e nos meios científicos, quando se trata de focalizar a atividades de pesquisa em geral realizada pelos professores da educação básica. (LUDKE, 2004, p. 105)

Considerando a nossa experiência docente na formação de professores matriculados nos distintos cursos de licenciatura da UFOP e que posteriormente atuarão na educação básica, temos observado o quão esta temática ainda se apresenta como um tanto controversa. Isto é, há uma diferença de sentido entre o ser "professor/pesquisador" para os alunos que estão cursando as disciplinas de licenciatura, portanto, encontram-se na categoria do "vir-a-ser" professor e aqueles que igualmente estão matriculados nas disciplinas, mas já são professores em exercício.

No caso destes últimos, além de licenciandos, já atuam como professores das séries iniciais e já têm uma trajetória no magistério. No entanto, embora reconheçam a importância das exigências apresentadas pelos documentos oficiais quanto à formação pretendida, ou seja, 
professores-pesquisadores, percebem alguns limites para o desenvolvimento desta competência.

Em exercício proposto a um grupo de alunos do curso de licenciatura da UFOP, percebemos que muitos destes enfatizaram a exterioridade da universidade frente a sua experiência e seus saberes, a inutilidade das teorias elaboradas "por quem não conhece a sala de aula" e procuraram valorizar a própria experiência como fonte de saber e poder. Alguns excertos produzidos por eles diante da questão: "Você concorda que, para o exercício de sua atividade docente, a experiência é mais relevante do que o conjunto de teorias elaboradas a partir de uma natureza cientifica especifica?" Algumas respostas foram bastante elucidativas da percepção que possuem acerca da problemática em questão:

falta autonomia, palavras, valorização para formalizar o saber advindo da prática (L., licencianda do curso de Letras da UFOP e professora das séries iniciais).

O que falta é a ousadia de divulgar a sua prática de forma escrita, porque as palavras faladas vão-se enquanto as graficamente impressas ficam, formalizando a prática de nosso dia-a-dia (C., licencianda do $4^{\circ}$ período do curso de Letras da UFOP).

Relatos como estes evidenciam um certo ressentimento dos professores por não terem seus saberes e sua experiência valorizados. Refutam o fato de que as pesquisas são elaboradas por quem não está no chão da sala de aula. Parece que no vértice da pirâmide encontra-se a universidade com seus saberes e a fabricação de uma nova teoria e, na sala de aula, os alunos, prontos a receberem em cascata todo o conhecimento que deve ser aplicado em sala de aula. Entretanto, sabemos que o conhecimento de qualquer disciplina emana indissoluvelmente da prática e da reflexão teórica sobre esta prática.

Temos ainda outros excertos, que nos dizem:

A pesquisa escolar, em sua maioria, se restringe a situações específicas, seu “corpus empírico" é muito limitado. A realidade da sala de aula é mais ampla, exige algo que as pesquisas que vêm sendo desenvolvidas não abrange. Os professores não têm acesso às pesquisas, os livros são caros e a sua distribuição é péssima. (M.L., licencianda do $4^{\circ}$ período do curso de Letras da UFOP) 
As teorias estudadas durante a formação do professor, muitas vezes fogem um pouco do cotidiano da maioria das escolas do ensino fundamental e médio, principalmente as públicas. [...] Nesses casos, o professor tem que desempenhar vários papéis, e o primeiro deles é o de "adaptador", isto é, ele deve "traduzir" e adaptar as teorias acadêmicas ao contexto escolar em que atua. (R., licencianda do curso de Letras da UFOP e professora de educação infantil)

Nestes excertos, o que podemos perceber é o distanciamento existente entre a contribuição da pesquisa para a prática pedagógica. $\mathrm{Ou}$ seja, estes licenciandos/professores analisam o fato de que muitas vezes a produção científica não consegue contribuir para a melhoria da escola e das dimensões do processo de ensino/ aprendizagem. Entretanto, há que se considerar uma certa distância existente entre o trabalho cotidiano do professor e o saber formalizado por uma disciplina ou campo científico. Tal percepção, por si só, pode ser um indicativo da realidade que se encontra para além do cotidiano escolar. A percepção das contradições que extrapolam o domínio da sala de aula permite ao professor "distinguir, na escola, entre o que depende dele e o que não depende; entre o modificável e o intransformável, entre a terra cultivável e o cimento armado" (BAUDELOT, 1991, p. 38).

Nossos alunos não conseguirão, não têm base para isso" ou "não temos tempo a perder com projetos que não levam a nada". Some-se a isso o fato de que os professores, em sua maioria, lecionam em várias turmas, de escolas diferentes, e realmente não têm tempo de realizar pesquisas ou apropriar-se da pesquisa alheia e adaptá-la à sua realidade. (R., licencianda do curso de Letras da UFOP e professora de educação infantil)

Aqui verificamos ainda o quanto o professor se sente "descrente" do seu potencial para o desenvolvimento da habilidade de fazer pesquisa. Todavia, sabemos que esta sensação de fracasso, quando bem orientada, é um bom antídoto contra certos voluntarismos que nos fazem crer que para mudar basta querer. Ao contrário, reconhecer o sentimento de fracasso já representa um bom começo para uma práxis da ação:

a realidade escolar, como parte da realidade social, não se muda nem pela boa vontade dos professores nem pelos decretos do governo. Os obstáculos encontrados não têm sua origem na "resistência à mudança 
dos professores" ou na "força de inércia do sistema", devem-se muito mais fundamentalmente às funções sociais reais do sistema escolar nas sociedades burguesas. (BAUDELOT, 1991, p. 37).

Percebemos, diante do exposto, o quanto esse exercício de reflexão se efetiva enquanto prática de investigação e experimentação. O refletir sobre a prática de certa forma estimula o professor a desenvolver uma atitude como pesquisador, como produtor de saber e do saber fazer docente.

\section{APROXIMAÇÕES FINAIS}

Na impossibilidade de concluir, resta-nos a percepção de que para além das exigências das políticas educacionais no que se refere ao estabelecimento de novas competências e habilidades para atuação dos professores, há de se esperar a contribuição da universidade como destaque na formação para a pesquisa dos professores, seja através do curso de graduação, especialização ou pós-graduação.

Desta forma é que percebemos que as mudanças que vêm ocorrendo nas políticas educacionais recentes têm influenciado na formação e atuação do professor de forma a não reconhecê-lo mais como aquele que constrói a sua profissão somente a partir de modelos e conhecimentos preestabelecidos. Em outros termos, já não se pode mais conceber o professor da educação básica como aquele que absorve passivamente o conhecimento produzido pelos pesquisadores acadêmicos.

Isto porque, durante muito tempo de sua formação, os professores construíram sua profissão na paráfrase, conforme lembra Esteban (2002), ou seja, na imposição de modelos, na transmissão de conhecimentos já produzidos.

quem vive o cotidiano da escola não se reconhece no texto teórico, sentindo-se negado; quem teoriza precisa estar atento para não se abstrair da realidade da escola, exorcizando o que possa tumultuar a racionalidade do constructo elaborado. (Esteban, 2002, p. 14)

As respostas de muitos licenciandos ilustram a inquietação diante de um documento oficial que elege a pesquisa como elemento fundante 
para prática do professor e, ao mesmo tempo, revela as dificuldades que encontram diante de condições adversas no dia-a-dia de seu exercício laboral para legitimar a importância de um saber que se alimenta tanto da teoria quanto da prática, tal como evidenciam a fala dos alunos:

O professor se vê perdido. Não sabe como aplicar uma pesquisa ao cotidiano, como torná-la útil, como transmiti-la ao aluno sem a perda do conteúdo "tradicionalmente ministrado", principalmente porque há uma falta crônica de recursos e de apoio didático, não somente com os alunos, mas principalmente com os próprios educadores. (F., licenciando do $4^{\circ}$ período do curso de Letras da UFOP)

A produção da pesquisa educacional muitas vezes é feita em âmbito geral, vinculada a cotidianos diversos, tornando-se inadequada ao desenvolvimento dos alunos e, sem referências para a seleção, organização e elaboração dos conteúdos. (G., licenciando do $4^{\circ}$ período do curso de Letras da UFOP)

Por não atender às necessidades dos professores e estar muitas vezes distante da realidade vivida por eles na sua prática diária, deixa de ter a devida importância. Os resultados da pesquisa, quando chegam, não condizem mais com a realidade vivenciada pelo professor naquele momento. O próprio sistema educacional, quando permite novas experimentações, elas são pré-determinadas, com a implantação de certos programas educacionais, os chamados "pacotes prontos". (R., licenciando do $4^{\circ}$ período do curso de Letras da UFOP)

A prática docente, muitas vezes percebida como a cisão entre o homo faber e o homo sapiens, difundiu a falsa impressão de que a docência se caracteriza pela aplicação imediata de metodologias formuladas em alguma instância "superior" à sala de aula, fazendo dela o lócus da ação, como se o agir desobrigasse o pensar. Por isso que observamos, entre nossos licenciandos, um possível resquício ainda desta concepção, presente na dificuldade com que alguns professores em exercício têm em conjugar a pesquisa em sua prática.

Entretanto, embora reconheçamos a importância de um documento oficial que privilegia, nos cursos de formação, uma atenção especial à construção do chamado professor/pesquisador, constatamos que uma política apenas de cunho vertical não é suficiente para a sua execução, mas a conjugação de esforços de todos aqueles inseridos no processo educativo. 
A prática da pesquisa torna-se realmente central na formação continuada e na atuação do professor como elemento propulsor de mudanças diante da complexidade que envolve a ação docente. É a partir desta experiência em desenvolver uma prática investigativa que o professor poderá estimular os seus alunos para o exercício da busca e da descoberta.

\begin{abstract}
Face to the demands of current educational politics, we sought, in this article, to problematize the need of rethinking the educational formation and practice, reactivating the idea of forming the teacher/researcher. As analysis, we chose speeches of degree students of the Federal University of Ouro Preto. Although the importance of official documents is recognized in privileging, in the formation courses, the construction of the so call teacher/researcher, we verified that just a vertical politic is not enough for it's execution, but the conjugation of efforts of all those inserted in the educational process.
\end{abstract}

Key-words: teacher/researcher; teacher's formation; educational politics, degrees.

\title{
REFERÊNCIAS
}

ANDRE, M. O papel da pesquisa na formação e na prática dos professores.

3. ed. Campinas: Papirus, 2004.

BAUDELOT, C. A Sociologia da educação: para quê. In: Teoria \& Educação, n. 3, 1991.

BRASIL. Ministério da Educação. Parecer n.: CNE/CP 009/2001. Diretrizes Curriculares Nacionais para a Formação de Professores da Educação Básica, em nível superior, curso de licenciatura, de graduação plena

BRASIL. Ministério da Educação. Resolução n.: CNE/CP 001/2002. Institui Diretrizes Curriculares Nacionais para a Formação de Professores da Educação Básica, em nível superior, curso de licenciatura, de graduação plena

CASTRO, M. de; VILELA, R. A. T. Profissão Docente: refletindo sobre a experiência de Pesquisa na abordagem sócio-histórica. In: Itinerários de pesquisa-perspectivas qualitativas em sociologia da educação. Rio de Janeiro: DP\&A, 2003.

ESTEBAN, M. T. Professora-pesquisadora: uma práxis em construção. Rio de Janeiro: DP\&A, 2002. 
FIORENTINI, D. et al. Saberes docentes: um desafio para acadêmicos e práticos. In: GERALDI, C. et al. (Orgs.) Cartografias do trabalho docente. Campinas, SP: Mercado das Letras, 1998.

GARCIA, R. L. (Org.). Método: pesquisa com o cotidiano. Rio de Janeiro: DP\&A, 2003.

LUDKE, M (Org.). O professor e a pesquisa. Campinas, SP: Papirus, 2004.

Pesquisa em educação: conceitos, políticas e práticas. In: GERALDI, C. et al. (Orgs.) Cartografias do trabalho docente. Campinas, SP: Mercado das Letras, 1998.

OLIVEIRA, I. B. (Org.) Pesquisa no/do cotidiano das escolas. Rio de Janeiro: DP\&A, 2001.

PERRENOUD, P. Práticas pedagógicas, profissão docente e formação: perspectivas sociológicas. Portugal: Dom Quixote, 1993.

PEREIRA, E. M. Professor como pesquisador: o enfoque da pesquisa-ação na prática docente. In: GERALDI, C. (Org). Cartografias do trabalho docente: professor(a)-pesquisador(a). Campinas, SP: Mercado das Letras ALB, 1998.

SACRISTÁN, J. G. Consciência e ação sobre a prática como libertação profissional dos professores. In: NÓVOA, A. Profissão professor. Porto Editora, 1995.

TARDIF, M.; LESSARD, C.; LAHAYE, L. Os professores face ao saber. Esboço de uma problemática do saber docente. Teoria e Educação, n. 4, Porto Alegre: Pannônica, 1991.

TURA, M. de L. R. A observação do cotidiano escolar. In: Itinerários de pesquisa-perspectivas qualitativas em sociologia da educação. Rio de Janeiro: DP\&A, 2003.

ZEICNHER, K. Para além da divisão entre professor-pesquisador e pesquisador acadêmico. In: GERALDI, C. et al. (Orgs.) Cartografias do trabalho docente. Campinas, SP: Mercado das Letras, 1998. 
